\title{
The status of African elephant Loxodonta africana populations in South Africa
}

\author{
Yolanda Pretorius, Marion E. Garaï and Lucy A. Bates
}

\begin{abstract}
With an increase in poaching of elephants Loxodonta africana across Africa, it is vital to know exactly how many elephants remain and where they occur, to ensure that protection and management are planned appropriately. From a nationwide survey we provide current population and distribution data for elephants in South Africa. We consider the viability of elephant populations in the country, as well as some of the management techniques implemented and how effective these are in controlling elephant numbers. According to our surveys there were 28,168 elephants in South Africa as of December 2015, with $78 \%$ of these occurring in Kruger National Park and reserves bordering and open to the Park. Of the country's 78 discrete reserves that host elephants, $77 \%$ have populations of $<100$ elephants, which could mean they are not genetically viable. We discuss our findings in terms of the conservation value of South Africa's elephant reserves, and the animal welfare implications. We recommend that the fragmentation of elephant habitat in the country be addressed through a national elephant management strategy that promotes wildlife corridors between existing, neighbouring elephant reserves.
\end{abstract}

Keywords Contraception, elephant, fences, Loxodonta africana, population, South Africa, welfare

\section{Introduction}

\footnotetext{
frican elephants Loxodonta africana, categorized as Vulnerable on the IUCN Red List (Blanc, 2008), have been declining rapidly across the continent, largely as a result of increased poaching pressure and competition for resources with people and livestock (Bouché et al., 2011; Wittemyer et al., 2014; Chase et al., 2016). However, the elephant population in South Africa appears to have been increasing since 1992 (Hall-Martin, 1992; Slotow et al., 2005). Since the mid 1980s there has been an increase in the number of smaller, fenced reserves in South Africa that contain

Yolanda Pretorius (Corresponding author) Centre for Wildlife Management, University of Pretoria, Private Bag X20, Hatfield, 0028, South Africa E-mail yolanda4wildlife@gmail.com

MARIOn E. GARAÏ Elephant Specialist Advisory Group, Vaalwater, Limpopo, South Africa

Lucy A. Bates School of Psychology, University of Sussex, Brighton, UK

Received 24 March 2017. Revision requested 30 May 2017.

Accepted 18 September 2017. First published online 15 April 2018.
}

elephants, following translocations of juveniles who were spared from the culls conducted in Kruger National Park up to 1996 (Garaï et al., 2004). These smaller reserves, and the elephants within them, are owned and managed by various entities, including national or provincial level state-ownership, as well as communal or private ownership.

The first nationwide survey of elephant numbers in South Africa was conducted by Hall-Martin in 1992. This was followed by surveys in 1994 and 2001, conducted by the Elephant Managers and Owners Association. These surveys indicated a substantial increase in both elephant numbers and distribution range since the species was nearly extirpated from the country by hunting a century before (Garaï et al., 2004; Slotow et al., 2005). Further national surveys were conducted during $2012-2015$ by the Elephant Specialist Advisory Group of South Africa. Here we aim to collate this survey information and provide current data on total elephant numbers in South Africa, which is timely given the continuing debates regarding the future of ivory trading and the widespread threat of poaching (e.g. Cruise, 2016). In South Africa perimeter fences are used extensively to denote land ownership and contain wildlife within designated protected areas (Snijders, 2012). However, such fences often cut off the historical movement routes of elephants and change the way they use the landscape, giving rise to artificial distribution patterns and unique management problems. Confining elephants within a closed, fenced area is known to increase their localized impact on vegetation, often with a consequent reduction in the available browse for other species, such as the black rhinoceros Diceros bicornis (Landman et al., 2013). Hence, elephant populations in fenced reserves need to be limited and controlled, but this presents its own ethical challenges (Lötter et al., 2008). Moreover, small population sizes may result in incomplete social structures, which have previously been shown to lead to behavioural abnormalities such as hyperaggression (Slotow et al., 2000).

In open systems, elephant societies are made up of a multi-tiered social structure, with the mother and calf unit at the core (first tier) of a family group (second tier) that consists of a matriarch, her maternal sisters and their adult female daughters and dependent offspring (c. 10 individuals on average; Lee $\&$ Moss, 1986), with females typically spending their whole lives with other close female relations. Related family groups fuse from time to time as bond groups (third tier), and when several families or bond groups join each other they form what is known as a clan (fourth tier) (Wittemyer et al., 2005). Bulls start to leave their natal 
families when they reach adolescence, and link up with other bulls to form bachelor herds. As bulls grow older they may become more solitary but still interact with other males to maintain dominance hierarchies (Poole, 1994). However, males of all ages prefer to associate with older bulls, and proximity to mature bulls is thought to play an important role in learning and socialization (Evans \& Harris, 2008).

To consider the viability of the discreet, fenced elephant populations in South Africa, we assess their genetic viability. This is difficult to determine in practice but Franklin (1980) proposed a theoretical minimum number of 50 breeding individuals, which keeps inbreeding at $1 \%$ per generation. Using this number as a rule of thumb, and taking demography and sex ratios into account, Sukumar (1993) suggested 100 elephants per population are needed to ensure a high probability of survival during the next 100 years. Estimates of a minimum viable population size for elephants vary (e.g. Armbruster \& Lande (1993) argue for a much greater number) but here we use Sukumar's figure of 100 elephants as a simple proxy to determine how many of South Africa's discreet elephant populations are likely to be genetically viable at present.

However, given our knowledge of elephant society, and the evidence from several sources that suggests behavioural problems can manifest in elephants living in abnormal social groups that deviate from the natural pattern (Slotow et al., 2000; Bradshaw et al., 2005), we also propose the concept of a socially viable minimum group size. This may be a novel idea in conservation assessments but it has previously been suggested as necessary by philosophers and animalwelfare researchers (Donaldson \& Kymlicka, 2011), and we argue it is particularly pertinent to elephants as a highly social species (McComb et al., 2001; Byrne et al., 2009). This suggestion is supported by the evidence that elephants strive to maintain normal social units in the face of population breakdown (Goldenberg et al., 2016) and that the absence of normal social units in a population may result in elephants behaving abnormally or maladaptively (Slotow et al., 2005; Shannon et al., 2013).

If elephants require a normal social hierarchy to prevent maladaptive behaviour, we suggest that each population must include all the main tiers, relationships and dominance hierarchies that are evident in large, open societies. We suggest that at least three family groups (i.e. three second-tier groups, which can form a bond group and/or a fourth-tier clan) and four independent bulls (two young adults and two mature bulls) may be a minimum requirement for a socially viable elephant population (i.e. one that gives the elephants access to a normal social hierarchy and thus facilitates normal social behaviour). Given the mean family group size of 10 elephants (Lee \& Moss, 1986), we therefore suggest that 34 elephants (30 adult cows and dependent offspring, plus four independent bulls) is a workable and necessary minimum number for normal social behaviour.

Using these proxy figures as minimum numbers for genetically and socially viable populations, we aim to determine (1) how many elephants there are in South Africa, (2) where they are distributed and, crucially, (3) how many of these populations are genetically and socially viable.

\section{Methods}

Members of the Elephant Specialist Advisory Group committee produced a list of reserves in South Africa that currently host elephants, using data from previous elephant counts (Elephant Managers and Owners Association, 2001, unpubl. data; Slotow et al., 2005) as well as information from provincial nature conservation authorities detailing which reserves applied for permits to introduce elephants since 2001. A search was also conducted on Google (Google Inc., Menlo Park, USA) using the keywords 'elephants South Africa' to check whether any reserves previously unknown to us were advertising that they hosted elephants. This generated a list of 90 reserves and protected areas that were potentially home to free-ranging elephants in 2015.

We determined that three reserves had removed all their elephants since 2001, resulting in a list of 87 reserves, protected areas or parks containing elephants in South Africa. Between 2012 and 2015 we contacted owners and managers from each of these reserves and asked them to fill in a questionnaire. The questionnaire comprised inquiries about the location and ownership of the property; elephant numbers; counting techniques; population structure; dates elephants were introduced to the reserve; number of introductions, removals and deaths; and the management techniques implemented (including any use of the porcine zona pellucida (PZP) vaccine for immunocontraception of cows, vasectomies of bulls, and/or the use of gonadotropin releasing hormone vaccine $(\mathrm{GnRH})$ ).

South African National Parks, Mpumalanga Tourism and Parks Agency and the Associated Private Nature Reserves bordering Kruger National Park provided us with elephant numbers from aerial counts conducted during the study period in and around the Park. As nine private reserves that border the Park are open to the Park, and thus elephants can move between them, we consider all of these elephants as a single population, which we refer to as the Greater Kruger elephant population. On this basis there are 78 discreet elephant populations in South Africa. For most of the descriptive analysis, reserves were categorized according to the provinces in which they occurred and whether they were owned by the state or a community or private entity. As, theoretically, the entire South African elephant population was counted, there was no need to statistically test for changes in elephant numbers from the 
previous complete census. However, changes in ownership were tested using $\chi^{2}$ statistics.

To examine the effect of birth control and fences on elephant population size we used completed questionnaires from the 2012-2015 surveys (3-year interval), and the previous data from 2001 and 2005 (4-year interval). We calculated mean annual rates of population increase at 3-4 year intervals for the 27 reserves for which we had complete information on population sizes across these years and which indicated what type of birth control (vasectomy on bulls/ PZP vaccine on cows) they used. These rates were calculated by subtracting the first year of count data available for a reserve from the second year of count data available, divided by the number of years between the two counts and then expressed as a percentage. To compare rates of population increase between fenced and open populations we used data on the mean annual rates of increase in the Greater Kruger as part of an open system and published data on long-term studies in Amboseli (Moss, 2001) and Samburu (Wittemyer et al., 2013), also representing open systems. Using a $t$-test with a one-tailed distribution assuming unequal variances, we compared the difference in population increase rates between reserves that used birth control and those that did not, as well as between fenced and open systems.

All reserves surveyed made use of aerial counting techniques or had extensive monitoring programmes that made individual identification of all elephants on the property possible. Hence, we assume that all elephant numbers reported during our survey are a minimum estimate of elephant population sizes in South Africa as of December 2015.

\section{Results}

A total of 45 reserves at least partially answered our questionnaire, and 30 were returned completed. Total elephant numbers for the 42 remaining reserves were obtained from either the relevant state conservation authorities (provincial conservation bodies or South African National Parks) or follow-up telephone calls to private owners.

\section{Population size, distribution and rate of change}

Using our survey data and data provided to us by the national and provincial conservation authorities, we calculated that South Africa was home to an estimated 28,168 elephants as of December 2015, across the 87 reserves, parks and protected areas. This figure is substantially higher than the total population of 15,744 estimated in 2001, with an increase of nearly $89 \%$ over the 14 years.

The Greater Kruger area hosts $78 \%$ of South Africa's elephants (21,657 individuals), a similar proportion to the $82 \%$ in 2001 (then 12,924 individuals). Few elephants occur on community land, with $<_{1} \%$ (115 individuals) of the national

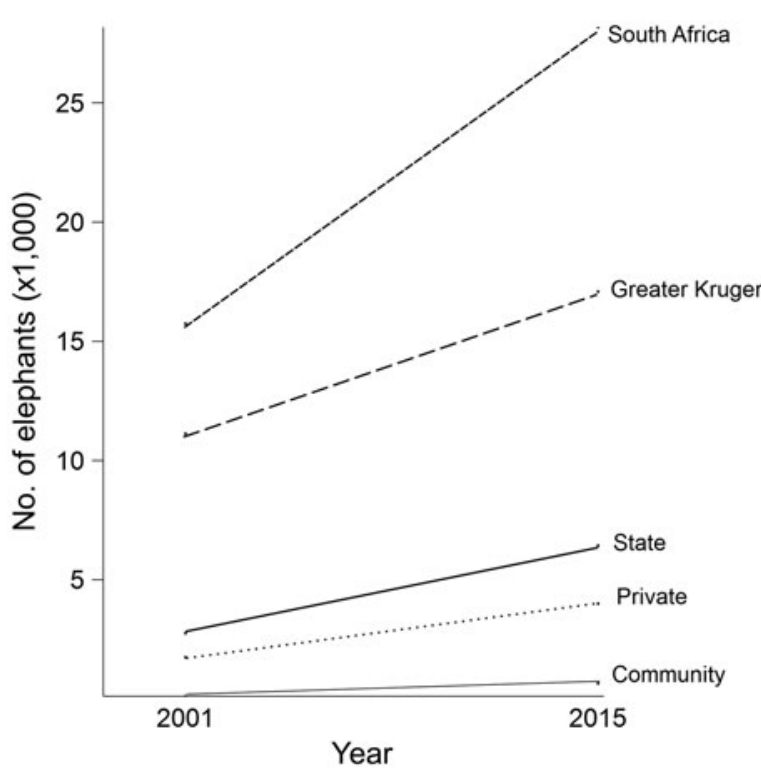

FIG. 1 Increases in elephant Loxodonta africana numbers in the Greater Kruger area and on additional communal, state, and privately owned land across South Africa between 2001 and 2015.

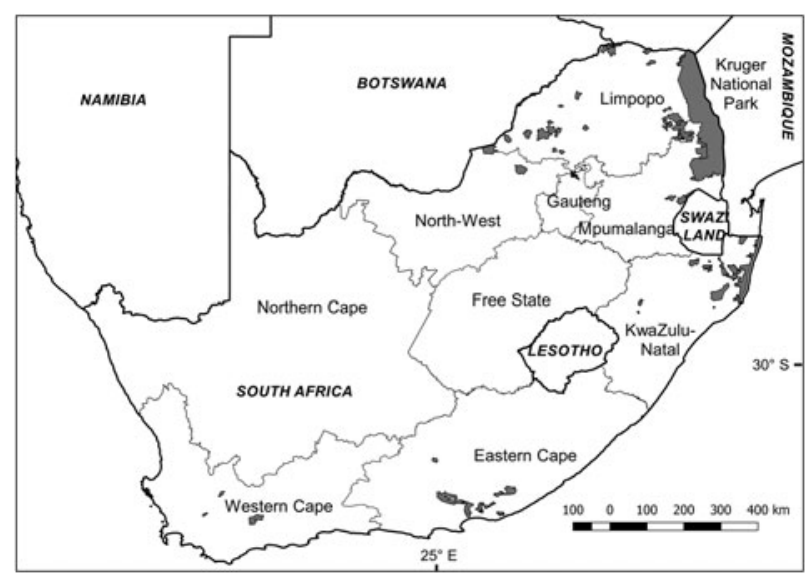

FIg. 2 Distribution of elephants in South Africa in 2015 (grey shading). Spatial data supplemented by the Elephant Specialist Advisory Group and the South African National Biodiversity Institute.

population on community-owned land in 2001, increasing to $2.3 \%$ ( 652 individuals) in 2015. The proportion of privately owned elephants increased from $17.5 \%(2,755)$ in 2001 to $22.8 \%(6,430)$ in 2015 , with the actual number of privately owned elephants more than doubling. Although elephant numbers have increased significantly on private, state and communal land since 2001, the proportion of ownership between these entities has remained the same ( $\mathrm{P}>0.05$; Fig. 1).

South Africa's elephant populations are spread across seven of the country's eight provinces (Fig. 2). Only the Northern Cape Province, in the arid north-west of the country, has no elephants. Gauteng Province is home to a population of just 13 individuals, and Limpopo Province hosts the 
majority of the country's elephants, even excluding those found within the Greater Kruger area. Many of Limpopo's non-Kruger elephants occur on privately owned land, the rest being divided between state and community-owned reserves. North-West Province hosts the most state-owned elephants $(1,246)$ outside Greater Kruger (Table 1; Fig. 3).

During 2001-2015 26 reserves introduced elephants for the first time. These introductions occurred mainly in the Eastern Cape (8o elephants on six reserves), KwaZulu Natal (149 elephants on five reserves) and Limpopo (78 elephants on five reserves; Table 1). All of these reserves are privately owned, and the elephants introduced to them originated from various existing reserves, including in the Greater Kruger area (Table 1).

On average, during 2001-2015 the change in elephant populations in all provinces in South Africa, including the Greater Kruger area, has been positive, with increases of $1.8 \%$ (Limpopo private land) to $4.3 \%$ per year (Kruger private land; Fig. 4).

Thirty-three reserves answered our questions about nonlethal management interventions. Of these, 13 confirmed that they use the PZP vaccine on elephant cows as a means of birth control, and four stated that they had vasectomized one or more of their bulls as a means of birth control. Ten reserves reported using GnRH on their bulls, and did so in an attempt to decrease aggression and signs of musth rather than primarily as a contraceptive measure.

The elephant population increase is significantly higher for reserves that do not use birth control (5.53\%) compared to reserves that do $(0.18 \%)(\mathrm{N}=27, \mathrm{P}<0.05)$. However, there was no significant difference in population increases between reserves that use birth control and open systems $(\mathrm{N}=14, \mathrm{P}>0.05)$, whereas increases were significantly higher in reserves that did not use birth control than in open systems $(\mathrm{N}=19, \mathrm{P}<0.05)$ (Fig. 5).

\section{Population viability}

There are 78 discrete elephant populations in South Africa (considering the 10 Greater Kruger reserves as one population). However, currently, these populations can mix and interbreed only if individual elephants are artificially translocated (Garaï et al., 2004). Among the 78 reserves, 21 small populations occur on reserves that share a communal boundary fence, which, if opened, would result in nine larger populations. Another eight populations occur on reserves that border a trans-frontier park containing freeroaming elephant populations.

Of the 78 discrete populations in South Africa, $59 \%$ are not socially viable according to our proxy minimum of 34 elephants per population. Of the 33 reserves that provided data on elephant age and sex structures, nine hosted either no bulls or only one bull, and 17 had fewer than four bulls;

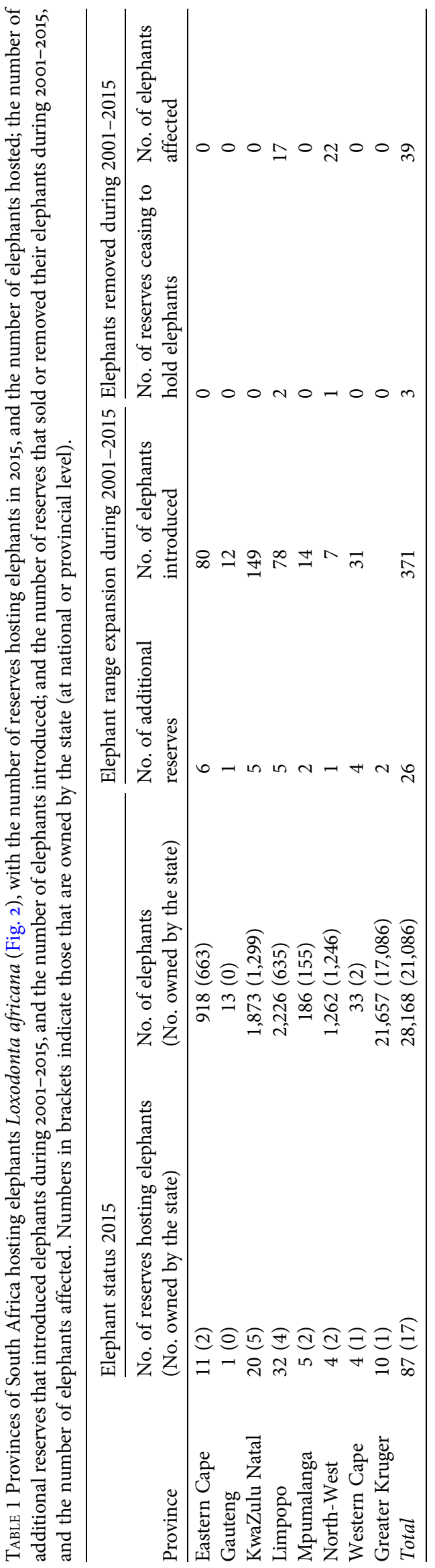




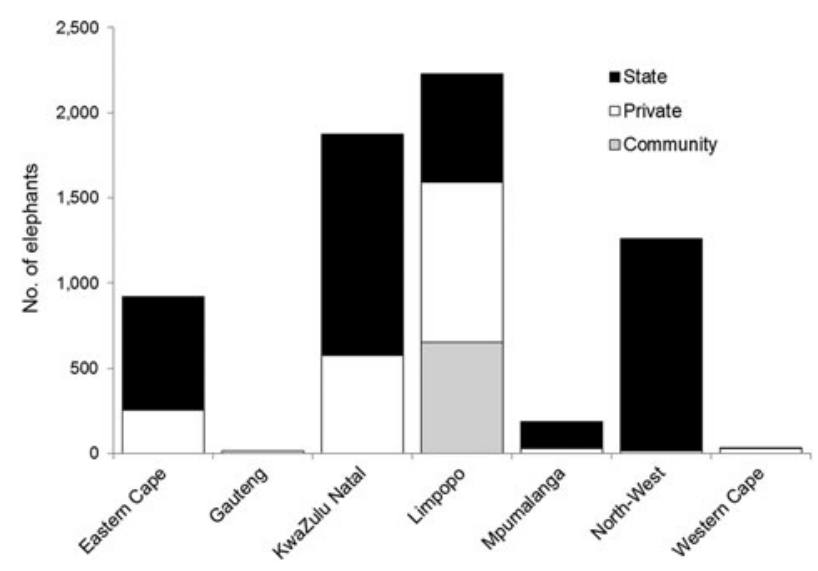

Fig. 3 Number of elephants (outside Greater Kruger) on state, private and communal land in South Africa's provinces in 2015.

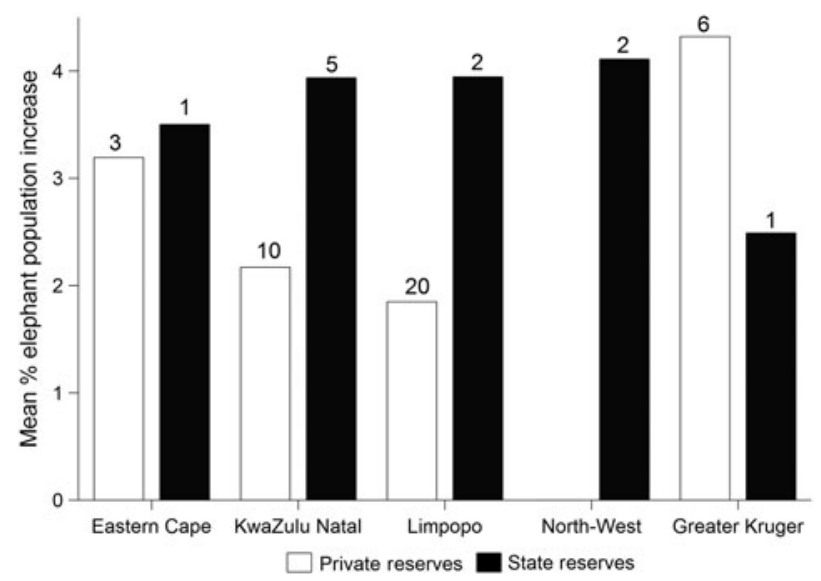

FIG. 4 Mean annual population increase of elephants in South Africa during 2001-2015 (by province), with numbers of reserves for which data were available indicated over the bars.

$53 \%$ of the elephant populations we know about do not contain socially viable male populations.

Furthermore, $77 \%$ of the populations were not genetically viable, according to the criteria of Franklin (1980) and Sukumar (1993); in 6o reserves the elephant population comprised fewer than 100 individuals. Thirty-eight of the reserves that had fewer than 100 elephants in 2001, and thus could not be considered to be genetically viable, still have fewer than 100 . Only three of the genetically unviable populations are state-owned, one in each of Eastern Cape, Western Cape and Limpopo Provinces. All four of the nationally owned, South African National Parks-managed populations are genetically viable, with a minimum population size of at least 240 individuals. Conversely, at least $90 \%$ of all the privately owned reserves in all seven provinces contain fewer than 100 elephants.

\section{Discussion}

Since Hall-Martin's national elephant survey in 1992, South Africa's elephant numbers have more than tripled and,

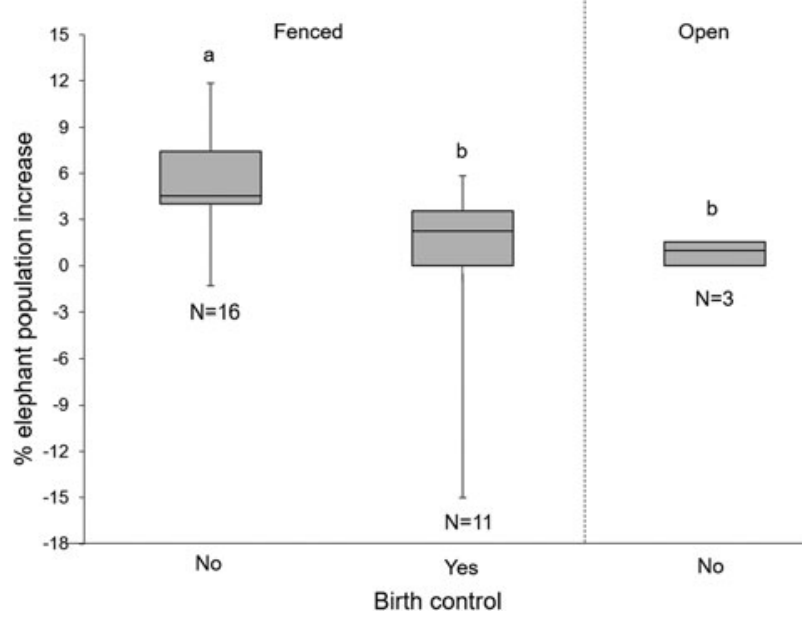

Fig. 5 Difference in mean annual percentage elephant population increase between reserves using birth control, reserves that do not, and open and fenced systems (boxes indicate the lower and upper quartile, and whiskers the lowest and highest percentage increases; $a$ is significantly higher than b).

unlike in most countries in Africa, where poaching is rife (Chase et al., 2016), the elephant population continues to increase. This is true of all provinces that host elephants, and although in some cases it is attributable to the introduction of translocated elephants to new reserves, it is mostly population expansion within established ranges.

Our total population estimate for South Africa $(28,168)$ is substantially higher than the estimate published as part of the Great Elephant Census (17,433; Chase et al., 2016). The Great Elephant Census was based on a flown transect in Kruger National Park, whereas our study also included all the private reserves adjacent and open to Kruger, as well as fenced parks and reserves in the rest of the country. Although we acknowledge the limitations of our population estimates in that, other than for the Great Elephant Census, different pilots and counters were used in the aerial counts conducted for each reserve, we believe that even allowing for potential errors introduced by inexperienced counters, our estimate at least gives a true representation of the minimum number of elephants in the country.

However, numbers and general population statistics do not always reflect the stability of a species, particularly one with such complex social structures and spatial requirements as the African elephant. Elephant societies in an open landscape are multi-tiered (Wittemyer et al., 2005), with genetic relatedness and the presence of experienced elders playing an important role in the stability and functioning of the society (McComb et al., 2001; Gobush \& Wasser, 2009; Goldenberg et al., 2016). We have shown that South Africa's elephants are widely fragmented, and most populations consist of only single families and/or incomplete bull hierarchies.

In an initial attempt to measure and assess the potential impacts of this fragmentation, we introduced the concept of 
a socially viable population. Much has been written about the problems associated with keeping elephants in unnatural social groups (Bradshaw et al., 2005; Gobush \& Wasser, 2009), and it is apparent that elephants that do not have access to the kind of society found in large, open populations often demonstrate abnormal, possibly aggressive, or maladaptive behaviour (e.g. Slotow et al., 2000; Shannon et al., 2013). We argue, therefore, that the concept of a socially viable group is necessary for the improved management of elephants in fenced reserves. By allowing elephants to live in societies that better mimic natural social patterns and hierarchies, there is good reason to think that fewer behavioural problems will manifest. The minimum socially viable population size of 34 individuals that we used here was defined according to average family sizes in natural elephant populations, and the minimum number of family groups and bulls that together could provide the same hierarchical structure known in open elephant populations. However, we must be clear that this number is, at this stage, purely an estimate and further research is required to both validate the utility of the concept and determine the most appropriate minimum number. However, based on current arguments and knowledge, the majority of elephant reserves in South Africa do not have the number of elephants required for normal social functioning. Many populations are not genetically or socially viable.

Much has been written about the problems associated with keeping elephants in unnatural groups (Slotow et al., 2000; Bradshaw et al., 2005; Clubb et al., 2008; Gobush \& Wasser, 2009; Shannon et al., 2013), and socially unviable groups almost certainly cause or contribute to a range of behavioural and management problems that are frequently reported in South Africa (Slotow et al., 2000).

In South Africa wildlife may be privately owned, and many reserves keep elephants for the economic benefits of photographic safaris and/or hunting. Such reserves may dedicate large tracts of land to conservation, which might otherwise be used for farming or other commercial purposes (Cousins et al., 2008), but the social requirements of species within these reserves must also be taken into consideration. Currently the National Norms and Standards for the Management of Elephants in South Africa (Department of Environmental Affairs and Tourism, 2008) does not include any mention of keeping socially and genetically viable populations. We recommend that such standards be included in future.

In accordance with the findings of Delsink et al. (2006), our analysis shows that currently used techniques of birth control (the PZP vaccine and vasectomy of bulls) are effective in reducing elephant population increases, as is often required on small reserves. However, it is apparent from our surveys that a third of the reserves that completed the questionnaire use $\mathrm{GnRH}$ with the sole aim of reducing aggression in elephant bulls (de Nys et al., 2010). The probable cause of this aggression, namely the lack of complete and normally functioning bull hierarchies, is generally ignored, even though hyperaggression in young adult male elephants in the absence of older experienced bulls has been well described (Slotow et al., 2000). Given that little is known about the long-term consequences of GnRH use on fertility, we caution against using this as a simple remedy for male aggression, and encourage managers to consider and manage the underlying causes of any aggressive behaviour.

We believe that emphasis should now be placed on opening the fences between neighbouring elephant reserves to increase population and range sizes, and reduce the need for intensive artificial management. An increasing number of reserves across Africa are now erecting (or considering the use of) fences to manage and contain elephant and other wildlife populations (Woodroffe et al., 2014; Durant et al., 2015). We urge policy makers to at least consider the impacts on population viability when making such decisions in the future. With numbers of elephants plummeting across the continent (Chase et al., 2016), we must make sure that as many populations as possible are and remain viable, and accurate counting is a necessary first step towards this goal.

Despite the increases in its elephant population, South Africa has a mixed history of interaction with elephants, with indiscriminate hunting for ivory in the late 19th century, the establishment of fenced provincial and national parks hosting elephants in the early 2oth century, culling to control elephant numbers in these fenced parks in the mid 2oth century, translocation of elephants to new fenced reserves in the late 20 th century, the use of contraception since the beginning of the 21st century, and most recently the use of hormonal vaccines to modify behaviour (Scholes \& Mennell, 2008). We hope the next era of elephant history in South Africa will be one of defragmentation of elephant habitat and formation of corridors to facilitate the restoration of viable, functioning elephant societies.

\section{Acknowledgements}

We thank Chris Rautenbach for her perseverance and dedication in eliciting questionnaire responses from elephant owners and managers, and all members of the Elephant Specialist Advisory Group (South Africa) for their time, effort and funds. Moreover, we thank the nature conservation authorities in South Africa for contributing to our dataset, and the South African National Biodiversity Institute for providing spatial data for the map.

\section{Author contributions}

YP and MEG conceived the study, designed the methodology and collected the data. YP and LAB analysed the data. All authors contributed to writing and revision of the article and approved the final version for publication. 


\section{References}

Armbruster, P. \& Lande, R. (1993) A population viability analysis for African elephant (Loxodonta africana): how big should reserves be? Conservation Biology, 7, 602-610.

B LANC, J. (2008) Loxodonta africana. In The IUCNRed List of Threatened Species 2008: e.T12392A3339343. Http://dx.doi.org/10.2305/IUCN.UK. 2008.RLTS.T12392A3339343.en [accessed 28 September 2017].

Bouché, P., Douglas-Hamilton, I., Wittemyer, G., Nianogo, A. J., Doucet, J.-L., Lejeune, P. \& Vermeulen, C. (2011) Will elephants soon disappear from West African savannahs? PLoS ONE, 6(6), e20619.

Bradshaw, G.A., Schore, A.N., Brown, J.L., Poole, J.H. \& Moss, C.J. (2005) Elephant breakdown. Nature, 433, 807.

Byrne, R.W., Bates, L.A. \& Moss, C.J. (2009) Elephant cognition in primate perspective. Comparative Cognition \& Behavior Reviews, 4, 65-79.

Chase, M.J., Schlossberg, S., Griffin, C.R., Bouché, P.J.C., Djene, S.W., ElKan, P.W. et al. (2016) Continent-wide survey reveals massive decline in African savannah elephants. PeerJ, 4, e2354.

Clubb, R., Rowcliffe, M., Lee, P., Mar, K.U., Moss, C. \& Mason, G.J. (2008) Compromised survivorship in zoo elephants. Science, 322,1649 .

Cousins, J.A., Sadler, J.P. \& Evans, J. (2008) Exploring the role of private wildlife ranching as a conservation tool in South Africa: stakeholder perspectives. Ecology and Society, 13(2), 43, http://www. ecologyandsociety.org/vol13/iss2/art43/.

Cruise, A. (2016) Breaking: Pro-ivory trade country's change of heart upends elephant debate. National Geographic, http://news. nationalgeographic.com/2016/10/elephants-ivory-trade-botswanacites/.

Delsink, A.K., van Altena, J.J., Grobler, D., Bertschinger, H., Kirkpatrick, J. \& Slotow, R. (2006) Regulation of a small, discrete African elephant population through immunocontraception in the Makalali Conservancy, Limpopo, South Africa. South African Journal of Science, 102, 403-405.

de Nys, H.M., Bertschinger, H.J., Turkstra, J.A., Colenbrander, B., Palme, R. \& Human, A.M. (2010) Vaccination against GnRH may suppress aggressive behaviour and musth in African elephant (Loxodonta africana) bulls: a pilot study. Journal of the South African Veterinary Association, 81, 8-15.

Department of Environmental Affairs and Tourism (2008) National Norms and Standards for the Management of Elephants in South Africa in terms of section 9 of the National Environmental Management: Biodiversity Act, 2004 (Act No. 10 of 2004).

Donaldson, S. \& Kymlicka (2011) Zoopolis: A Political Theory of Animal Rights. Oxford University Press, Oxford, UK.

Durant, S.M., Becker, M.S., Creel, S., Bashir, S., Dickman, A.J., Beudels-Jamar, R.C. et al. (2015) Developing fencing policies for dryland ecosystems. Journal of Applied Ecology, 52, 544-551.

Evans, K.E. \& Harris, S. (2008) Adolescence in male African elephants, Loxodonta africana, and the importance of sociality. Animal Behaviour, 76, 779-787.

FRANKLIN, I.R. (1980) Evolutionary change in small populations. In Conservation Biology: An Evolutionary Perspective (eds M.E. Soulè \& B.A. Wilcox), p. 135. Sinauer Associates, Sunderland, USA.

Garaï, M.E., Slotow, R., Carr, R.D. \& Reilly, B. (2004) Elephant reintroductions to small fenced reserves in South Africa. IUCN, 3, 27.

Gobush, K.S. \& W ASSER, S.K. (2009) Behavioural correlates of low relatedness in African elephant core groups of a poached population. Animal Behaviour, 78, 1079-1086.

Goldenberg, S.Z., Douglas-Hamilton, I. \& Wittemyer, G. (2016) Vertical transmission of social roles drives resilience to poaching in elephant networks. Current Biology, 26, 75-79.
Hall-Martin, A.J. (1992) Distribution and status of the African elephant Loxodonta africana in South Africa, 1652-1992. Koedoe, 35, 65-88.

Landman, M., Schoeman, D.S. \& Kerley, G.I.H. (2013) Shift in black rhinoceros diet in the presence of elephant: evidence for competition? PLoS ONE, 8(7), e69771.

Lee, P.C. \& Moss, C.J. (1986) Early maternal investment in male and female African elephant calves. Behavioral Ecology and Sociobiology $18,353-361$.

Lötter, H.P.P., Henley, M., Fakir, S. \& Pickover, M. (2008) Ethical considerations in elephant management. In Elephant Management: A Scientific Assessment of South Africa (eds R. J. Scholes \& K.G. Mennell), pp. 406-445. Wits University Press, Johannesburg, South Africa.

McComb, K., Moss, C.J., Durant, S.M., Baker, L. \& Sayialel, S. (2001) Matriarchs as repositories of social knowledge in African elephants. Science, 292, 491-494.

Moss, C.J. (2001) The demography of an African elephant (Loxodonta africana) population in Amboseli, Kenya. Journal of Zoology, 255, 145-156.

Poole, J.H. (1994) Sex differences in the behaviour of African elephants. In The Differences Between the Sexes (eds R.V. Short \& E. Balaban), pp. 331-346. Cambridge University Press, Cambridge, UK.

Scholes, R.J. \& Mennell, K. (eds) (2008) Elephant Management: A Scientific Assessment of South Africa. Wits University Press, Johannesburg, South Africa.

Shannon, G., Slotow, R., Durant, S.M., Sayialel, K.N., Poole, J., Moss, C. \& MсСомв, K. (2013) Effects of social disruption in elephants persist decades after culling. Frontiers in Zoology, 10, 62.

Slotow, R., van Dyk, G., Poole, J., Page, B. \& Klocke, A. (2000) Older bull elephants control young males. Nature, 408, 425-426.

Slotow, R., Garaí, M.E., Reilly, B., Page, B. \& Carr, R.D. (2005) Population dynamics of elephants re-introduced to small fenced reserves in South Africa. South African Journal of Wildlife Research, $35,23-32$.

SNIJDERS, D. (2012) Wild property and its boundaries-on wildlife policy and rural consequences in South Africa. Journal of Peasant Studies, 39, 503-520.

Sukumar, R. (1993) Minimum viable populations for elephant conservation. Gajah, 11, 48-52.

Wittemyer, G., Daballen, D. \& Douglas-Hamilton, I. (2013) Comparative demography of an at-risk African elephant population. PLOS ONE, 8(1), e53726.

Wittemyer, G., Douglas-Hamilton, I. \& Getz, W.M. (2005) The socioecology of elephants: analysis of the processes creating multitiered social structures. Animal Behaviour, 69, 1357-1371.

Wittemyer, G., Northrup, J.M., Blanc, J., Douglas-Hamilton, I., OMONDI, P. \& BURnH AM, K.P. (2014) Illegal killing for ivory drives global decline in African elephants. Proceedings of the National Academy of Sciences of the United States of America, 111, 13117-13121.

Woodroffe, R., Hedges, S. \& Durant, S.M. (2014) To fence or not to fence. Science, 344, 46-48.

\section{Biographical sketches}

Yolanda Pretorius's research focuses on the foraging ecology and welfare of African elephants, including rehabilitation of captive elephants into the wild. MARION GARAI's research interests include the behaviour of translocated elephants in South Africa and the welfare of elephants in European zoos. LU CY BATES's research focuses on differences in social behaviour and culture of African elephants across the continent. All authors are on the steering committee of the Elephant Specialist Advisory Group (South Africa). 